\title{
REGISTOS DO ATOR PLURAL. BERNARD LAHIRE NA SOCIOLOGIA PORTUGUESA [João Teixeira Lopes (org.), 2012, Porto, Edições Afrontamento]
}

\author{
Nuno Nunes \\ Instituto Universitário de Lisboa (ISCTE-IUL), CIES-IUL, Lisboa, Portugal
}

A obra coletiva Registos do Ator Plural. Bernard Lahire na Sociologia Portuguesa, sob a organização de João Teixeira Lopes, constitui um oportuno contributo para o desenvolvimento da problemática das desigualdades sociais nas sociedades contemporâneas. Bernard Lahire é hoje uma referência sociológica central na reflexão sobre o social à escala individual, mais concretamente no estudo dos processos de socialização e de constituição das disposições sociais, em sociedades marcadas pela diferenciação, diversidade contextual e desiguais constrangimentos e possibilidades. É no estado incorporado e das variações intraindividuais e interindividuais dos comportamentos culturais e sociais que as desigualdades sociais são por Lahire problematizadas, (con)substanciadas nos modos de cada indivíduo se pensar a si mesmo, tendo por referência as suas circunstâncias sociais, desigualdades objetivas modeladoras (cri)ativas de singularidades individuais que permitem entender a forma como estas se apropriam das múltiplas realidades que compõem o mundo social dos agentes. Longe do modelo das identidades pós-modernas, as biografias tornam-se, então, cada vez mais complexas, atuando (pluralmente) dentro de um campo finito de possibilidades, como diria Gilberto Velho.

A relevância de Bernard Lahire nas ciências sociais recobre os domínios da epistemologia, da teoria e da metodologia. No seu trabalho científico, Lahire não dissocia a atenção epistemológica quanto ao ofício de sociólogo e aos seus instrumentos de investigação, e a procura de perspetivas teóricas avançadas, sustentadas empiricamente.

O seu posicionamento de extensão e reelaboração do fundamental legado conceptual de Pierre Bourdieu está a fazer nascer novas possibilidades de análise sociológica, sistematizando o mais possível os conceitos de habitus, de transmissibilidade das disposições, de homologias e de herança cultural. Lahire constrói um modelo teórico que permite pensar a ação e o ator entre disposições heterogéneas e contextos variáveis, observando as práticas no âmbito de uma sociologia da pluralidade disposicional e contextual, com lugar para as relações intersubjetivas, para os domínios de atividade e para as próprias situações de interação, ativando ou enfraquecendo disposições diferentemente constituídas e com graus desiguais de robustez, que, combinando-se com apetências, crenças, cálculos e estratégias, compõem a vida quotidiana fortemente marcada por conflitos estruturais.

As diferentes escalas de observação do social enriquecem o trabalho sociológico na análise dos problemas em estudo. A biografia sociológica é o instrumento central das propostas de Bernard Lahire, a que melhor permite reconstituir os diferentes quadros de socialização dos agentes e as diferentes experiências por que 
estes passam. Como refere Sandra Lima Coelho, uma das coautoras do livro que aqui se apresenta, a grande inovação que ilustra o contributo de Bernard Lahire "consiste numa mudança, precisamente, ao nível do objeto de estudo: o seu desígnio passa por analisar indivíduos singulares, apoiado metodologicamente na técnica dos retratos sociológicos, construídos com base em entrevistas aprofundadas, retendo, deste modo, as matrizes incrustadas em cada indivíduo enquanto produto de experiências de socialização passadas" (p. 94). E neste livro a metodologia dos "retratos sociológicos" constitui a principal ferramenta de compreensão das disposições sociais em múltiplas esferas da vida social.

O livro Registos do Ator Plural. Bernard Lahire na Sociologia Portuguesa é composto por cinco capítulos, antecedidos de um prefácio da autoria do próprio Bernard Lahire, e por uma breve introdução ao livro por parte de João Teixeira Lopes, o organizador da obra. O principal objetivo do livro é resgatar uma série de contributos alicerçados em pesquisas empíricas elaboradas em Portugal a partir da sociologia de Lahire, desafiando a heuristicidade da rede de conceitos do programa de pesquisa do autor francês. No primeiro capítulo, da autoria de Ana Caetano, discute-se teoricamente a articulação entre reflexividade individual e disposições; no segundo capítulo, da autoria de Isabel Silva Cruz, a tese do ator plural permite aprofundar o conhecimento do consumo enquanto prática social; no terceiro capítulo, por Pedro dos Santos Boia e João Teixeira Lopes, procura-se apreender a variação disposicional consoante as esferas de socialização estruturais e culturais que caracterizam uma determinada trajetória de vida; no quarto capítulo, Sandra Lima Coelho, através da análise de percursos biográficos de voluntários associativos, parte da teoria lahiriana e do seu desenho metodológico para o estudo da ação coletiva; no capítulo 5, Ana Roseira Rodrigues e Tânia Leão analisam as práticas culturais dos estudantes do ensino superior, a partir dos resultados do projeto "Os Estudantes e os Seus Trajetos no Ensino Superior. Sucesso, Insucesso, Fatores e Processos, Promoção de Boas Práticas", coordenado por António Firmino da Costa e João Teixeira Lopes.

Ana Caetano analisa a reflexividade individual no quadro de uma teoria disposicionalista, uma vez que o trabalho de Bernard Lahire constitui um contributo fundamental para pensar e operacionalizar o conceito de reflexividade. Os agentes relacionam-se diferentemente com as suas disposições, detendo graus diferenciados de reflexividade nos múltiplos contextos sociais onde atuam. Como refere Ana Caetano, "os processos de reflexividade só podem ser realmente analisados tendo em conta a complexidade interna de cada ator, o que implica abordar a singularidade individual sem esquecer que se trata de sujeitos socializados, que se encontram na interseção de diferentes esferas e forças sociais" (p. 17). As lógicas da ação reflexiva e de sentido prático articulam-se, "coexistem na ação humana e estão permanentemente a suceder-se e a intercalar-se no quotidiano. Não é possível, por um lado, viver apenas com base na escolha racional, no interesse ou na estratégia, e as práticas, por outro, não são exclusivamente orientadas pelo hábito e pela rotina" (p. 20).

Isabel Silva Cruz, no capítulo 2, propõe alicerces para uma sociologia à escala individual aplicada à esfera do consumo, testando empiricamente a homogeneidade / heterogeneidade dos sistemas de disposições e as relações de condicionamento que 
o poder / volume e espécies de capitais exercem sobre as práticas de consumo. O género, a idade, o capital escolar, o tipo de agregado e a fase do ciclo de vida familiar, o lugar de classe e o rendimento constrangem as práticas de consumo. Verifica-se a associação entre o consumo e o desempenho de papéis por parte dos agentes, que remetem para o status, para competências e formas de poder. É reforçada a perspetiva "de que o consumo é a expressão de um querer mais ou menos constrangido pelos deveres sociais (regras de prescrição), pelos saberes adquiridos (socializações múltiplas, contextos de interação), e pelos poderes (económico, cultural, relacional, entre outros)" (p. 48).

No capítulo 3, Pedro Boia e João Teixeira Lopes debruçam-se sobre as experiências das mulheres clubbers, a partir da análise do retrato sociológico de Maria, no contexto periférico pobre da área metropolitana do Porto. O objetivo da investigação consistiu em compreender as experiências das mulheres e os processos de construção identitária de classe e género, no âmbito da sua participação nas (sub)culturas ligadas às festas de música eletrónica de dança. Verifica-se a existência de "homologias" entre a segmentação da cena clubbing e outras segmentações de cariz estrutural. Observa-se uma interseção entre as práticas culturais tradicionais, populares, de massas e o clubbing, em detrimento de uma compartimentação estanque.

No capítulo 4, Sandra Lima Coelho, a partir das trajetórias biográficas, procura decifrar as motivações dos voluntários de uma associação de comércio justo. A análise da pertença familiar e da trajetória de vida dos entrevistados evidenciou algumas das características estruturais da sociedade portuguesa, nomeadamente a trajetória intergeracional de mobilidade social ascendente com investimento na educação. A partilha de um sistema de valores e de universos simbólicos convergentes com a causa do comércio justo constitui um fator indispensável de organização associativa, fomentadora de patrimónios de ação coletiva perante as desigualdades e injustiças sociais, princípios e critérios que denodadamente regem o comércio justo.

Ana Roseira Rodrigues e Tânia Leão fecham esta obra coletiva, mostrando como a combinação de capitais (culturais, económicos e simbólico) da família de origem, é importante e decisiva para as práticas culturais na idade adulta e marca também a relação criada com o ensino superior. A par da família ou do grupo de amigos, a instituição universidade contribui igualmente com a sua ação socializadora. As sociabilidades são a prática mais citada entre os estudantes do ensino superior entrevistados, influenciando a estruturação dos estilos de vida durante este período de vida dos jovens. Como salientam Rodrigues e Leão, "as sociabilidades geradas em contexto académico, muitas vezes exteriores ao recinto institucional [...], existem como espaços de aproximação sociais, não pela atenuação ou esbatimento de desigualdades, mas pela quantidade de redes sociais que esses locais podem acolher. Essa profusão de redes, pode favorecer uma abertura face às relações estabelecidas, o que permite o alargamento de redes e o contacto com práticas culturais legítimas, no domínio da receção cultural e também da criação / expressão, confirmando assim a ação do grupo de pares como responsável pela sensibilização e/ou socialização cultural" (p. 149). 
Concluindo, este é um livro que, ao incorporar criativamente o património científico de Bernard Lahire, projeta no presente e no futuro da investigação social as enormes potencialidades sociológicas congregadas na obra do autor francês. As virtudes de uma sociologia à escala individual, que aprofunde o espaço interno dos agentes em conjugação fecunda com os ambientes externos da ação, e suas respetivas escalas meso e macrossociais, certamente enriquecem a análise dos fatores subjetivos e dos fatores objetivos presentes na estruturação das desigualdades sociais contemporâneas.

Nuno Nunes. Investigador do CIES-IUL, Instituto Universitário de Lisboa (ISCTE-IUL). E-mail: nuno.nunes@iscte.pt 